УДК 621.434-242.004.67

\title{
ИСПОЛЬЗОВАНИЕ ВТОРИЧНЫХ МАТЕРИАЛОВ ПРИ ВОССТАНОВЛЕНИИ РАБОТОСПОСОБНОСТИ ВТУЛОК ПОДШИПНИКОВ СКОЛЬЖЕНИЯ
}

\author{
Пилипенко Станислав Владимирович1, \\ 44-08@mail.ru \\ Фруцкий Виктор Александрович1, \\ Fruzki@mail.ru \\ Дудан Александр Витальевич1, \\ DudanAV@mail.ru \\ 1 Полоцкий государственный университет, \\ Беларусь, 211440, г. Новополоцк, ул. П. Блохина, 29.
}

\begin{abstract}
Актуальность работы обусловлена необходимостью ремонта втулок, имеющих рабочий износ, повышения антифррикционных характеристик трибосопряжений, экономии дорогостоящего сырья и внедрения ресурсосберегающих технологий. Вопрос экономии дорогостоящих материалов или замены их на менее дорогостоящие, а также применение отходов металлообрабатывающих производств не вызывает сомнений. Обеспечение повышенных значений нагрузок и скоростей скольжения при общем снижении стоимости сопряжений и соизмеримых межремонтных периодов достигается путем применения отходов стружки и проведения экономного динамического легирования на микроуровне материалами, способными улучшить эксплуатационные показатели сопряжения в целом. Снижение уровня антропогенного влияния достигается вследствие применения относительно безотходных методов восстановления.

Цель: создать трибосопряжение, эфффективно работающее при заданных условиях эксплуатации, при этом ограничивая количество потерь дорогостоящих ресурсов и сводя к минимуму негативное влияние на окружающую среду. Для этого применяется основа из измельченных металлоотходов с использованием экономного динамического легирования.

Методы: теоретические исследования стойкости предложенного материала, конструкции сопряжения и метода его нанесения; расчет технологических параметров нанесения материала в зависимости от условий эксплуатации.

Результаты. Определено наилучшее значение линейных параметров элементарных стружечных отходов, оптимальное значение легирующих элементов для данных условий эксплуатации трущихся пар. Разработана технология получения материалов с прогнозируемыми свойствами, с возможностью регулировки отдельных свойств материалов в зависимости от реальных условий эксплуатации. Разработанная технология ремонта тяжелонагруженных подшипников скольжения, работающих в неблагоприятных условиях эксплуатации, проверена в условиях современного машиностроительного предприятия.
\end{abstract}

\section{Ключевые слова:}

Экономия георесурсов, получение покрытий из отходов механической обработки, экономное легирование, антифрикционный материал из вторичного сырья, плазмообразующий газ, ресурсосберегающие технологии.

\section{Введение}

Подшипники скольжения, как неотъемлемая часть крупных агрегатов и механизмов, работают в сложных условиях трения и подвергаются относительно высоким скоростям износа [1-5]. Значительная степень износа подшипника может привести к выводу из строя узла или даже машины в целом. Поэтому вопрос замены таких деталей становится достаточно актуальным. К примеру, при ремонте прессового оборудования часто, при необходимости, заменяют втулки подшипников скольжения. Так, в прессе ПБ-6332Б замена четырех втулок общей массой 28 кг приводит к значительной экономии материальных ресурсов. В условиях современного предприятия с целью сохранения георесурсов и экономии средств предприятия заменяемые в ходе ремонтного цикла подшипники рационально подвергать ремонту. Таким образом продлевается срок службы подшипника, экономятся материальные ресурсы предприятия, в какой-то мере снижается антропогенное воздействие деятельности человека на окружающую среду [6]. Важно иметь приемлемую в ценовом отношении качественную технологию восстановления изнашиваемых деталей.
Также важно, чтобы в качестве сырья (по возможности) использовались отходы производства (например, металлическая стружка), а не дорогостоящие антифрикционные материалы [4]. При этом полученная поверхность детали должна обладать хорошими триботехническими свойствами. Исходя из этого, исследования в этой области являются актуальной задачей $[5,7]$. Целью исследования является разработка приемлемого антифрикционного материала подшипников скольжения с хорошими триботехническими свойствами и стоимостью меньшей, чем стоимость ранее применяемых материалов.

\section{Объект и предметы исследования}

Объектом исследования выступают процессы плазменной наплавки материалов, при использовании в качестве исходного сырья отходов производства. Предметы исследования - ресурсосберегающая технология восстановления трибосопряжений.

\section{Анализ исследований}

На рис. 1 показан типичный подшипник скольжения с жидкостным трением. Сухое трение в подшип- 
никах такого вида используется редко $[8,9]$, обеспечивают либо жидкостное, либо полужидкостное (смазка имеет слой толщиной около 0,1 мкм) [8-10].

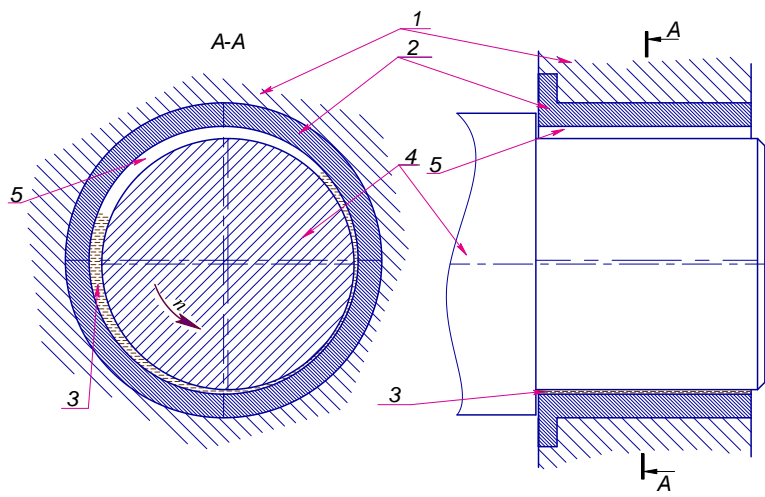

Рис. 1. Схема подшипника скольжения с жидкостным трением [6, 11-14]: 1 - корпус; 2 - вкладыш (неподвижен); 3 - масляный слой (зона нагнетания) $[15,16] ; 4$ - вал; 5 - зона разряжения [15, 16]; $n$-частота вращения вала

Fig. 1. Scheme of a sliding bearing with liquid friction [6, 11-14]: 1 - housing; 2 -insert (motionless); 3 - oil layer (oil injection zone) $[15,16] ; 4$ - shaft; 5 - rarefaction zone $[15,16] ; n$ - shaft rotation frequency

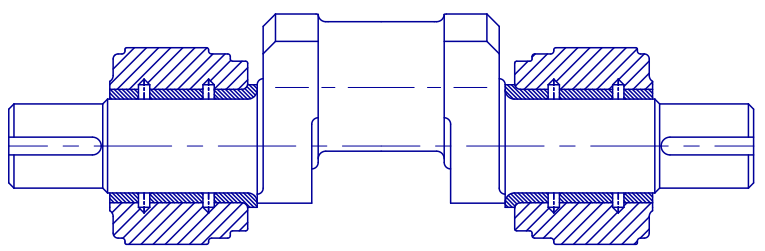

Рис. 2. Ведущчий вал главного исполнительного механизма кривошипно-иатунного пресса $[17,18]$

Fig. 2. Drive shaft of the main actuator of the crank press $[17,18]$

Таблица 1. Рекомендуемые режимы эксплуатации антифрикционных материалов [19]

Table 1. Recommended modes of operation of antifriction materials [19]

\begin{tabular}{|c|c|c|c|}
\hline \multirow[b]{2}{*}{$\begin{array}{c}\text { Материал } \\
\text { (указана марка } \\
\text { бронзы или чугуна) } \\
\text { Materials } \\
\text { (bronze or cast iron } \\
\text { grade is indicated) }\end{array}$} & \multicolumn{3}{|c|}{$\begin{array}{c}\text { Режимы эксплуатации (предельные) } \\
\text { Operating modes (ultimate) }\end{array}$} \\
\hline & $\begin{array}{c}\text { Давле- } \\
\text { ние (Р), } \\
\text { МПа } \\
\text { Pressure } \\
(\mathrm{P}), \mathrm{MPa} \\
\end{array}$ & $\begin{array}{c}\text { Скорость } \\
\text { скольжения } \\
\text { (V), м/c } \\
\text { Sliding } \\
\text { velocity (V), } \\
\text { m/s } \\
\end{array}$ & $\begin{array}{l}{[\mathrm{PxV}]} \\
\mathrm{M} \Pi \mathrm{M} \cdot \mathrm{M} / \mathrm{c} \\
\mathrm{MPa} \cdot \mathrm{m} / \mathrm{s}\end{array}$ \\
\hline $\begin{array}{l}\text { AЧC-1 } \\
\text { AChS }\end{array}$ & $0,05-9,0$ & $2,0-0,2$ & $0,1-1,8$ \\
\hline $\begin{array}{l}\text { AЧC-3 } \\
\text { AChS - } 3\end{array}$ & $0,1-6,0$ & $3,0-0,75$ & $0,3-4,5$ \\
\hline $\begin{array}{l}\text { AЧB-1 } \\
\text { AChV - } 1\end{array}$ & $0,5-12$ & $5,0-1,0$ & $2,5-12$ \\
\hline $\begin{array}{l}\text { AЧK-1 } \\
\text { AChK - } 1\end{array}$ & $0,5-12$ & $5,0-1,0$ & $2,5-12$ \\
\hline $\begin{array}{l}\text { БрОЦС 5-5-5 } \\
\text { BrOCS 5-5-5 }\end{array}$ & 8 & 3,0 & 12 \\
\hline $\begin{array}{l}\text { БрОФ } 10-1 \\
\text { BrOF } 10-1 \\
\end{array}$ & 10 & 10,0 & 15 \\
\hline $\begin{array}{l}\text { БрАЖ 9-4 } \\
\text { BRAG } 9 \text { - } 4\end{array}$ & 15,0 & 4,0 & 12 \\
\hline Полимеры/Polymers & до $5 /$ to 5 & до $1 /$ to 1 & - \\
\hline
\end{tabular}

Как видно из рис. 1, при работе подшипника между втулкой и валом образуется специфический клинообразный зазор, в который увлекается определенное количество смазки, выбрасываемой с обратной стороны. В зоне контакта трибопары можно различить зону нагнетания и зону разряжения $[15,16]$.

В данном случае подшипники являются опорой для коленчатого вала, который приводит возвратнопоступательное движение шатуна (рис. 2). В целом в механизме можно выделить рабочий (прямой) и холостой ход [17-19].

Давление и скорость скольжения - основные рабочие режимы, определяющие работу антифрикционного материала в подшипниках скольжения (табл. 1).

\section{Основной материал}

В рассматриваемом исполнительном механизме кривошипно-шатунного пресса используются цельнометаллические втулки из бронзы марки БрОФ 10-1. В ходе эксплуатации периодически контролируют зазор трибосопряжения. В случае достижения предельной величины зазора втулки демонтируют и утилизируют как лом цветного материала. При ремонте заменяются все четыре втулки. Масса одной втулки равна 7,0 кг, однако общий вес одновременно утилизируемых деталей достигает 280 кг (рис. 1).

Анализ работы втулок подшипников скольжения, который был проведен в кузнечном цехе Минского подшипникового завода, показал следующее:

a) из-за конструктивного расположения узла затруднена возможность монтажа или демонтажа втулок, что уменьшает частоту данных ремонтных мероприятий;

б) втулки являются основной опорой коленчатого вала и воспринимают нагрузки во время рабочего хода от шатуна пресса [18, 20-22];

в) наблюдается неравномерное распределение нагрузок по рабочей поверхности коленчатого вала (рис. 3) $[18,20-22]$;

г) трибосопряжения работают под воздействием переменной динамической нагрузки;

д) наблюдается повторно кратковременный режим работы узла при скорости скольжения $V=3 \mathrm{~m} / \mathrm{c}$ и давлении $P=5$ МПа;

е) вид трения трибопары «вал-втулка» граничный;

ж) смазочный материал в зону трибосопряжения закачивается через специальные технологические каналы;

3) из-за наличия на участке станков заточной и шлифовальной групп трибопары работают в условиях запыленности рабочего помещения. На оборудовании отсутствуют пылезащитные уплотнения и кожухи. Смазочный материал постоянно загрязняется песком и пылью, в которой содержится кварц и корунд с твердостью 18 и 23 ГПа соответственно.

Металлографические исследования используемых для производства вкладышей антифрикционных материалов, которые проводились на комплексе Nikon Epi Phot 200 BD, установили:

- вкладыши из литых оловянистых бронз изготовлены методом литья; 
- бронза вкладышей имеет резко выраженную дендритную структуру (рис. 4);

- периферийные зоны имеют меньшее содержание олова, чем дендриты, от чего они имеют более легкоплавкую структуру большей твердости;

- исследуемый материал соответствует типу структуры Шарпи I, состоит из мягкой матрицы $\alpha$-фазы с равномерно расположенными интерметаллидными упрочняющими фазами в виде $\mathrm{Cu}_{3} \mathrm{P}$ и $\mathrm{Cu}_{3} \mathrm{Sn}_{8}[23]$.

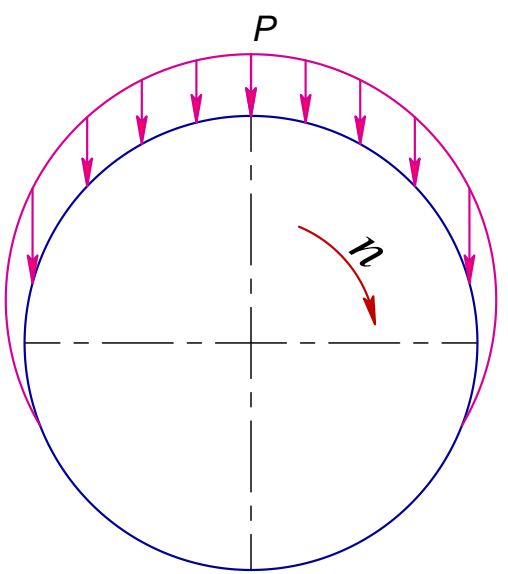

Рис. 3. Распределение радиальной нагрузки на валу кривошипно-шатунного механизма

Fig. 3. Radial load distribution on the shaft of the crank mechanism

Исходя из анализа режимов ( $\mathrm{P} \geq 5$ МПа, V $\geq 3$ м/с), сделан вывод о целесообразности использования сплавов с высокими антифрикционными свойствами, например, оловянисто-фосфористых бронз (табл. 1). Но есть возможность и более дешевого материала сплава на основе чугуна. Втулки из сплавов чугуна применяются не только для валов, имеющих повышенную твердость поверхности (более 55 HRСэ). В трибосопряжении с валом из улучшенной стали (2535 HRCэ) можно использовать мягкие антифрикционные чугуны марок АЧС-3, АЧВ-2, АЧК-2 при относительной дешевизне материала втулки.

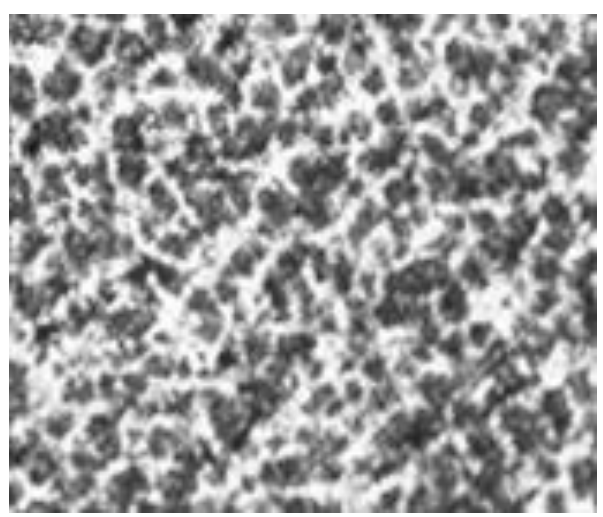

Puc. 4. Структура бронзы исследуемого вкладыша подшипника скольжения (марка бронзы - БрОФ 10-1, ×100)

Fig. 4. Bronze structure of the investigated plain bearing liner (designation of bronze - BrOF 10-1, ×100)
Для ремонта втулок подшипников скольжения предлагается использовать композиционный материал на основе отходов металлообработки серого чугуна (стружка), подвергаемый термодиффузионному легированию (с целью улучшения эксплуатационных характеристик). Дополнительное легирование чугунов производится как растворимыми в матрице чугуна элементами, так и не растворимыми. Последние образуют самостоятельные упрочняющие фазы. Повышение эксплуатационных характеристик серого чугуна производилось введением бора (несущая способность) и меди (повышение антифрикционных свойств).

Для ремонта вкладышей разработана технология с использованием композиционного материал, которая включает:

- сбор стружки и ее сепарирование;

- отсев нужных фракций $(0,06 \ldots 0,1$ мм);

- диффузионное насыщение чугунной стружки в подвижных расходуемых смесях [24].

В итоге получен диффузионно-легированный порошок, содержащий бор (до 1,5 \%) и медь (около $15 \%$ ), который необходимо нанести на изношенную поверхность втулок. Ремонт производился с использованием технологии плазменного напыления материала на установке ВДУ-ЗД. Пробно-аналитическим методом определены оптимальные режимы для нанесения подготовленного порошка на ремонтируемые поверхности втулки, которая имеет вид тонкостенной трубы с толщиной стенки около 4 мм.

В качестве плазмообразующего газа выбран аргон (расход до 20 л/мин). Диаметр относительного отверстия для истечения смеси - 3 мм. Порошковая смесь с фракцией 0,065-0,1 мм подавалась инжекторным способом. Угол наклона рабочей головки - 50-60 при расстоянии напыления в 80-120 мм. Скорость вращения напыляемой детали - 6 об/мин. Максимальный нагрев подложки $-500{ }^{\circ} \mathrm{C}$.

Таблица 2. Пористость материала при различной силе тока

Table 2. Material porosity at different amperage

\begin{tabular}{|c|c|c|c|c|}
\hline \multirow{2}{*}{$\begin{array}{c}\text { Материал } \\
\text { Material }\end{array}$} & \multirow{2}{*}{$\begin{array}{l}\text { Сила тока } \\
\text { Current } \\
\text { strength, A }\end{array}$} & \multicolumn{3}{|c|}{$\begin{array}{l}\text { Пористость } \\
\text { Porosity, \% }\end{array}$} \\
\hline & & $\min$ & $\max$ & mean \\
\hline $\begin{array}{l}\text { Стружка из нелегированного } \\
\text { чугуна марки СЧ-20 } \\
\text { Unalloyed cast iron shavings grade } \\
\text { SCh20 }\end{array}$ & 200 & 18 & 31 & 24 \\
\hline \multirow{3}{*}{$\begin{array}{l}\text { Стружка из нелегированного чу- } \\
\text { гуна марки СЧ- } 20+\text { бронза + медь } \\
\text { Unalloyed cast iron shavings grade } \\
\text { SCh } 20+\text { bronze + copper }\end{array}$} & 150 & 18 & 32 & 24 \\
\hline & 200 & 11 & 22 & 17 \\
\hline & 300 & 6 & 15 & 11 \\
\hline
\end{tabular}

Получение пористого материала слоя позволяет дополнительно повысить его эксплуатационные свойства. Поры будут накапливать и подавать смазочный материал в зону соприкосновения трущихся поверхностей. Определено, что на количественный состав пор значительное влияние оказывает сила тока применяемого источника. Так, уменьшение силы тока до 150 А приводит к существенному увеличению пористости материала из-за недостаточного нагрева напы- 
ляемых частиц, обладающих малой пластичностью. Увеличение же силы тока до 300 А уменьшает пористость наносимого материала более чем в два раза, так как прочность частиц повышается (табл. 2). Экспериментальным образом определено, что оптимальная сила тока напыления должна лежать ниже 300 А.

В табл. 3 показаны результаты исследований влияния технологических факторов на прочность сцепления $\sigma_{\text {сц }}$ покрытия.

Таблица 3. Прочность сиепления материала при плазменном напылении, $\sigma_{c u}$, Мпа

Table 3. Material adhesion strength during plasma spraying, $\sigma_{c u}, M P a$

\begin{tabular}{|c|c|c|c|c|}
\hline \multirow{2}{*}{$\begin{array}{l}\text { Сила тока } \\
\text { Current } \\
\text { strength, A }\end{array}$} & \multicolumn{3}{|c|}{$\begin{array}{c}\text { Дистанция напыления, } \\
\text { мм } \\
\text { Spraying distance, mm }\end{array}$} & \multirow{2}{*}{$\begin{array}{c}\text { Прочность сцепле- } \\
\text { ния, МПа } \\
\text { Adhesion strength, } \\
\text { MPa }\end{array}$} \\
\hline & 80 & 100 & 120 & \\
\hline 100 & 4,8 & 4,1 & 3,6 & $60 \ldots 65$ \\
\hline 200 & 7,9 & 7,2 & 6,6 & $70 \ldots 75$ \\
\hline 300 & 13,0 & 13,4 & 12,5 & $80 \ldots 90$ \\
\hline
\end{tabular}

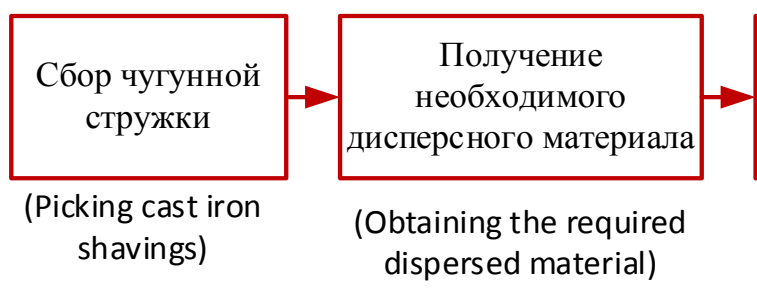

Экспериментальные исследования показали, что с ростом силы тока повышается и прочность сцепления; увеличение дистанции напыления приводит к умень-

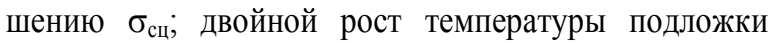
также приводит к резкому увеличению $\sigma_{\text {сц }}$ что объясняется не только дополнительной активацией поверхности, но и частичным связыванием адсорбированных поверхностных пленок бором; пластичность поверхности контакта также оказывает заметное влияние на прочность сцепления, а добавка в поверхностный слой легкоплавкой меди или напыление подслоя из никель-алюминиевого порошка повышает $\sigma_{\text {сц- }}$

Окончательное формирование микроструктуры композиционного материала осуществляется диффузионным отжигом в печи с защитной атмосферой. Температура отжига - $820 \ldots 860{ }^{\circ} \mathrm{C}$, продолжительность - 6 часов. Нагрев можно производить в герметичном контейнере, который на $3 / 4$ заполнен карбюризатором.

На рис. 5 показана общая схема предложенной технологии получения антифрикционного композиционного покрытия.

\begin{tabular}{|c|c|}
\hline $\begin{array}{c}\text { Нанесение } \\
\text { дисперсного материала поверхность }\end{array}$ & $\begin{array}{c}\text { Термообработка } \\
\text { отремонтированной } \\
\text { детали }\end{array}$ \\
\hline $\begin{array}{c}\text { (Application of } \\
\text { dispersed material to } \\
\text { the surface) }\end{array}$ & $\begin{array}{c}\text { (Heat treatment of a } \\
\text { repaired worn part) }\end{array}$
\end{tabular}

Pис. 5. Схема предложенной технологии получения антифрикционного композиционного покрытия

Fig. 5. Scheme of the proposed technology for producing anti-friction composite coating

В итоге получили структуру, близкую по конструкции структурам Шарпи I типа.

Далее приведены результаты металлографического и триботехнического исследования материалов полученного покрытия (рис. 6, табл. 4).

Сила тока и состав напыляемой смеси имеют превалирующее влияние на строение напиленного слоя (табл. 5). Необходимое строение покрытия до термообработки представлено на рис. 6. После окончательной термообработки покрытие обеспечивает необходимый уровень антифрикционных свойств (табл. 5). Эксплуатационные характеристики такого покрытия не уступают антифрикционным оловянистым бронзам, но значительно дешевле их.

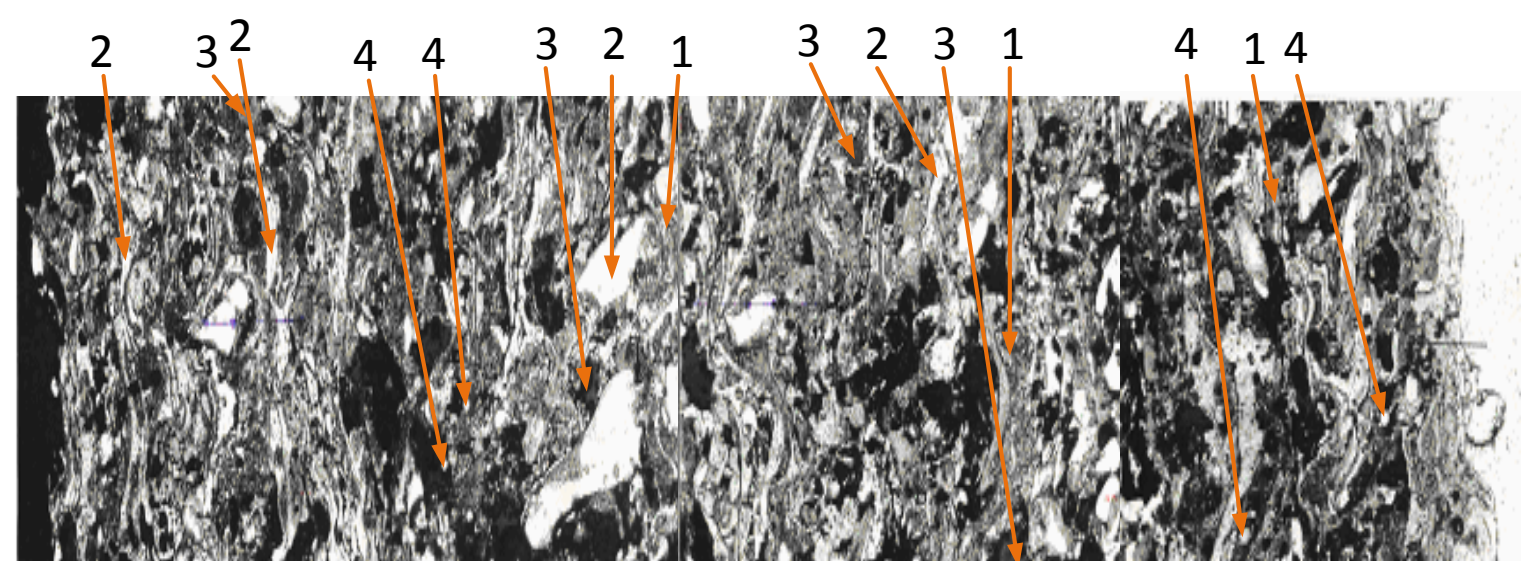

Pис. 6. Полученное плазменное покрытие из диффузионно-легированной бором и медью стружки серого чугуна (×300). 1 - мелкодисперсная бористая эвтектика; 2 - ламели $\alpha$-фазы с фрагментами перлита; 3 - медистые включения; 4 - боридные, борочементитные включения

Fig. 6. Plasma coating of gray cast iron chips diffusion-alloyed with boron and copper $(\times 300) .1-$ finely divided boron eutectic; 2 -lamellas of $\alpha$-phases with perlite fragments; 3 - copper inclusions; 4 -boride, boron-cementite inclusions 
Таблица 4. Влияние на структуру и пористость покрытия режимов нанесения материала

Table 4. Influence of material application modes on coating structure and porosity

\begin{tabular}{|c|c|c|c|}
\hline $\begin{array}{l}\text { Материал } \\
\text { Materials }\end{array}$ & $\begin{array}{c}\text { Сила тока } \\
\text { Current strength, A }\end{array}$ & $\begin{array}{l}\text { Микроструктура } \\
\text { Microstructure } \\
\times 300\end{array}$ & $\begin{array}{l}\text { Пористость } \\
\text { Porosity, \% }\end{array}$ \\
\hline $\begin{array}{l}\text { Стружка из нелегированного чугуна марки СЧ-20 } \\
\text { Unalloyed cast iron shavings grade SCh20 }\end{array}$ & 200 & & 9,54 \\
\hline $\begin{array}{l}\text { Стружка из нелегированного чугуна марки СЧ- } 20 \text { + } \\
\text { бронза } \\
\text { Unalloyed cast iron shavings grade SCh20 + bronze }\end{array}$ & 200 & & 8,67 \\
\hline \multirow{3}{*}{$\begin{array}{l}\text { Стружка из нелегированного чугуна марки СЧ- } 20 \text { + } \\
\text { бронза + медь } \\
\text { Unalloyed cast iron shavings grade SCh20 + bronze + } \\
\text { copper }\end{array}$} & 150 & & 8,27 \\
\hline & 200 & & 6,38 \\
\hline & 300 & & 4,15 \\
\hline
\end{tabular}

Таблица 5. Износ вкладышей образиов, м $^{*} E^{-5}$

Table 5. Wear of the liners of the samples, $m g * E^{-5}$

\begin{tabular}{|c|c|c|c|c|}
\hline \multirow{2}{*}{$\begin{array}{c}\text { Материал (указана марка } \\
\text { бронзы или чугуна) } \\
\text { Material (the grade of bronze } \\
\text { or cast iron is indicated) }\end{array}$} & \multicolumn{3}{|c|}{$\begin{array}{l}\text { Путь трения, м } \\
\text { Friction path, } \mathrm{m}\end{array}$} & \multirow{2}{*}{$\begin{array}{c}\text { Твердость, } \\
\text { HB } \\
\text { Hardness, } \\
\text { HB } \\
\end{array}$} \\
\hline & 2000 & 4000 & 6000 & \\
\hline $\begin{array}{l}\text { БрОЦС 5-5-5 } \\
\text { BrOCS 5-5-5 }\end{array}$ & 0,95 & 1,67 & 2,95 & 60 \\
\hline $\begin{array}{l}\text { БрAЖ 9-4 } \\
\text { BRAG 9 - } 4\end{array}$ & 0,85 & 1,19 & 1,75 & 130 \\
\hline $\begin{array}{l}\text { CY20 } \\
\text { SCh20 }\end{array}$ & 4,10 & 4,50 & 11,30 & 100 \\
\hline $\begin{array}{l}\text { БрОФ 10-1 } \\
\text { BrOF } 10-1\end{array}$ & 1,30 & 1,45 & $\mid$\begin{tabular}{|l|}
1,57
\end{tabular} & 90 \\
\hline $\begin{array}{l}\text { Предложенный сплав } \\
\text { Suggested alloy }\end{array}$ & 1,23 & 1,35 & 1,46 & 90 \\
\hline
\end{tabular}

Из табл. 5 видно, что эксплуатационные характеристики у полученного из отходов серого чугуна композиционного материала сопоставимы с показателями антифрикционных материалов на основе меди.

\section{Заключение}

Показана одна из возможностей применения в ремонтных производствах промышленных предприятий технологии получения материалов на основе метал-

\section{СПИСОК ЛИТЕРАТУРЫ}

1. Li S., An Q. Lubrication performance of planar thrust bearing with consideration of roughness of the surfaces // Journal of Engineering Tribology. - 2018. - № 47. - P. 356-361.

2. Mukutadze M.A., Khasyanova D.U. Optimization of the supporting surface of a slider bearing according to the loadcarrying capacity taking into account the lubricant viscosity depending on pressure and temperature // Journal of Machinery Manufacture and Reliability. - 2018. - № 47 (4). - P. 356-361.

3. Olt J., Maksarov V.V., Krasnyy V.A. Study of bearing units wear resistance of engines career dump trucks, working in fretting corrosion conditions // Записки Горного института. - 2019. № 235. - P. 70-77. лоотходов, которые обеспечивают необходимые эксплуатационные свойства трибосопряжений и позволяют экономить материальные средства предприятий.

Разработанная технология позволяет применять при ремонте втулок подшипников скольжения кривошипно-шатунных механизмов прессов синтезированный, относительно дешевый материал-заменитель дорогостоящих дефицитных бронз. Разработана технология получения материалов с прогнозируемыми свойствами, возможностью их регулирования в необходимых диапазонах. Полученное относительно дешевое покрытие по своим эксплуатационным свойствам не уступает известным антифрикционным материалам. Определено, что с применением плазмообразующего газа аргона (расход до 20 л/мин) диаметром отверстия для истечения смеси в 3 мм, подаваемой инжекторным способом порошковой смеси фракцией 0,065-0,1 мм, угле наклона рабочей головки - 50-60 и расстоянии напыления в 80-120 мм оптимальная сила тока напыления должна лежать ниже 300 А. Разработанная технология возможна к применению не только для ремонта втулок подшипников скольжения кривошипно-шатунных прессов, но и подшипников скольжения прокатных станов.

4. Основы трибологии (трение, износ, смазка) / А.В. Чичинадзе, Э.Д. Браун, Н.А. Буше, И.А. Буяновский, Ф.Г. Геккер, И.Г. Горячева, В.В. Гриб, Н.Б. Демкин, М.Н. Добычин, Ю.А. Евдокимов, С.М. Захаров, В.Я. Кершенбаум, Ю.М. Лужнов, Н.М. Михлин, А.Т. Романова, И.Г. Фукс. - М.: Машиностроение, 2001. - 664 с.

5. Review of recent advances in tribology / Y. Meng, J. Xu, Z. Jin, B. Prakash, Y. Hu // Friction. - 2020. - № 8. - P. 221-300.

6. Ligier J.-L., Noel B. Friction reduction and reliability for engines bearings // Lubricants. - 2015. - № 3. - P. 569-596.

7. Heat treatment-microstructure-mechanical/tribological property relationships in austempered ductile iron / T. Nasir, D.O. Northwood, J. Han, Q. Zou, G. Barber, X. Sun, P. Seaton // WIT 
Transactions on Engineering Sciences. - 2011. - № 71. - C. 159169.

8. Forming 4.0: smart machine components applied as a hybrid plain bearing and a tool clamping system / R. Kurth, R. Tehel, T. Päbler, M. Putz, K. Wehmeyer, C. Kraft, H. Schwarze // Procedia Manufacturing. - 2019. - № 27. - C. 65-71.

9. Кузяев И.М., Анисимов В.Н. Анализ температурных процессов в подшипниках скольжения с учетом трения // Problems of Tribology. - 2012. - № 1. - Р. 27-40.

10. Паровай Е.Ф., Ибатуллин И.Д. Актуальные проблемы надёжности узлов трения газотурбинных двигателей // Вестник Самарского государственного аэрокосмического университета. 2015. - № 3. - C. 375-383.

11. Plain bearing: pat. United States № 6.089.756; заявл. 12.03.1998; опубл. 18.07.2000. $-8 \mathrm{p}$.

12. 3D mechanical analysis of aeronautical plain bearings: validation of a finite element model from measurement of displacement fields by digital volume correlation and optical scanning tomography / A. Germaneau, F. Peyruseigt, S. Mistou, P. Doumalin, J.-C. Dupré // Optics and Lasers in Engineering. 2010. - V. 48. - № 6. - P. 676-683.

13. Numerical analysis of plain journal bearing under hydrodynamic lubrication by water / G. Gao, Z. Yin, D. Jiang, X. Zhan // Tribology International. - 2014. - № 75 - P. 31-38.

14. Иванов В.А., Еркаев Н.В. Анализ упругих деформаций в подшипнике скольжения // Фундаментальные исследования. 2015. - № 6. - C. 241-245.

15. Силуянова М.В., Фертиков А.О. Расчёт течения смазки в подшипнике скольжения редуктора авиационного двигателя // Вестник Самарского университета. Аэрокосмическая техника, технологии и машиностроение. - 2019. - Т. 18. - № 2. - С. 75-88.
16. Моделирование характеристик масляных и газовых подшипников скольжения методами вычислительной газовой динамики / А.О. Пугачёв, Ю.А. Равикович, Ю.И. Ермилов, Д.П. Холобцев, А.А. Матушкин // Вестник Самарского государственного аэрокосмического университета имени академика С.П. Королёва. - 2013. - № 3 (41). - Ч. 1. - С. 211-221.

17. Hlaváč J., Čechura M. Direct drive of $25 \mathrm{MN}$ mechanical forging press // Procedia Engineering. -2015 . - № 100. - P. 1608-1615.

18. Бурдуковский В.Г., Инатович Ю.В. Оборудование кузнечноштамповочных цехов. Кривошипные машины. - Екатеринбург: Изд-во Урал. ун-та, 2018. - 168 с.

19. Гаркунов Д.Н. Триботехника - М.: Машиностроение, 1999. $336 \mathrm{c}$.

20. Живов Л.И., Овчинников А.Г., Складчиков Е.Н. Кузнечноштамповочное оборудование. - М.: Изд-во МГТУ им. Н.Э. Баумана, 2006. - 560 c.

21. Chval Z., Cechura M. Optimization of power transmission on mechanical forging presses // Procedia Engineering. - 2014. № 69. - P. $890-896$.

22. Бочаров Ю.А. Кузнечно-штамповочное оборудование. - М.: ИЦ «Академия», 2008. - 480 с.

23. Фруцкий В.А. Антифрикционный материал из легированной бором и медью чугунной стружки для подшипников скольжения: дис... канд. техн. наук. - Новополоцк, 2006. - 135 с.

24. Штемпель О.П. Интенсификация диффузионного легирования металлических порошков для защитных покрытий в подвижных порошковых смесях: автореф. дис. ... канд. техн. наук. Новополоцк, 2003. - 23 с.

Поступила 12.12.2020 2.

\section{Информация об авторах}

Пилипенко C.B., кандидат технических наук, доцент кафедры автомобильного транспорта Полоцкого государственного университета.

Фруцкий В.А., кандидат технических наук, доцент кафедры автомобильного транспорта Полоцкого государственного университета.

Дудан A.B., кандидат технических наук, доцент кафедры автомобильного транспорта Полоцкого государственного университета. 
UDC 621.434-242.004.67

\title{
USE OF SECONDARY MATERIALS IN THE RESTORATION OF SLEEVE BEARING BUSHINGS EFFICIENCY
}

\author{
Stanislav V. Pilipenko 1 , \\ 44-08@mail.ru \\ Victor A. Frutski ${ }^{1}$, \\ Fruzki@mail.ru \\ Aleksandr V. Dudan', \\ DudanAV@mail.ru \\ 1 Polotsk State University, \\ 29, Blokhin street, Novopolotsk, 211440, Belarus.
}

The relevance of the work is caused by the need of repairing bushings that have working wear, to improve the anti-friction characteristics of tribo-tension, to save expensive raw materials and the need of resource saving technologies implementation. There is no doubt in saving expensive materials and replacing them with less expensive ones or using metalworking production waste. Provision of increased values of loads and sliding speeds with a general reduction in the cost of interfaces and comparable inter-repair periods is achieved by using chip waste and conducting economical dynamic alloying at the micro level with materials that can improve the performance of interfaces in general. The decrease in value of anthropogenic influence is achieved due to the use of relatively waste-free recovery methods.

The aim of the research is to create a tribo-voltage that works effectively under the specified operating conditions, while limiting the amount of waste of expensive resources and minimizing the negative impact on the environment. For this purpose a base of crushed metal waste is used with the application of economical dynamic alloying.

Methods: theoretical studies of the proposed material resistance, the design of the coupling and the method of its application; calculation of material application process parameters depending on operating conditions.

Results. The authors have determined the best value of linear parameters of elementary chip waste, the optimal value of alloying elements for these operating conditions and developed the technology for obtaining materials with pre-set properties with the ability to adjust individual properties depending on the actual operating conditions. The developed technology for repairing heavy-loaded plain bearings functioning under adverse operating conditions was tested in the conditions of a modern machine-building enterprise.

\section{Key words:}

Resource saving, obtaining coatings from mechanical processing waste, economical alloying,

anti-friction material from secondary raw materials, plasma-forming gas, eco-friendly application technology.

\section{REFERENCES}

1. Li S., An Q. Lubrication performance of planar thrust bearing with consideration of roughness of the surfaces. Journal of Engineering Tribology, 2018, no. 47, pp. 356-361.

2. Mukutadze M.A., Khasyanova D.U. Optimization of the supporting surface of a slider bearing according to the loadcarrying capacity taking into account the lubricant viscosity depending on pressure and temperature. Journal of Machinery Manufacture and Reliability, 2018, no. 47 (4), pp. 356-361.

3. Olt J., Maksarov V.V., Krasnyy V.A. Study of bearing units wear resistance of engines career dump trucks, working in fretting corrosion conditions. Notes of the Mining Institute, 2019, no. 235, pp. 70-77.

4. Chichinadze A.V., Brown E.D., Boucher N.A., Buyanovsky I.A., Gekker F.G., Goryacheva I.G., Grib V.V., Demkin N.B., Dobychin M.N., Evdokimov Yu.A., Zakharov S.M., Kershenbaum V.Ya., Luzhnov Yu.M., Mikhlin N.M., Romanova A.T., Fuks I.G. Osnovy tribologii (treniye, iznos, smazka) [Fundamentals of tribology (friction, wear, lubrication)]. Moscow, Mashinostroenie Publ., 2001. 664 p.

5. Meng Y., Xu J., Jin Z., Prakash B., Hu Y. Review of recent advances in tribology. Friction, 2020, no. 8, pp. 221-300.

6. Ligier J.-L., Noel B. Friction reduction and reliability for engines bearings. Lubricants, 2015, no. 3, pp. 569-596.

7. Nasir T., Northwood D.O., Han J., Zou Q., Barber G., Sun X., Seaton P. Heat treatment-microstructure-mechanical/tribological property relationships in austempered ductile iron. WIT Transactions on Engineering Sciences, 2011, no. 71, pp. 159-169.

8. Kurth R., Tehel R., Päbler T., Putz M., Wehmeyer K., Kraft C., Schwarze H. Forming 4.0: Smart machine components applied as a hybrid plain bearing and a tool clamping system. Procedia Manufacturing, 2019, no. 27, pp. 65-71.

9. Kuzyaev I.M., Anisimov V.N. Analysis of temperature processes in sliding bearings, taking into account friction. Problems of Tribology, 2012, no. 1, pp. 27-40. In Rus.

10. Parovay E.F., Ibatullin I.D. Actual problems of the reliability of friction units for gas turbine engines. Bulletin of the Samara State Aerospace University, 2015, no. 3, pp. 375-383. In Rus.

11. Ono A., Matsumura H., Niwa M., Nawa S., Shibayama T. Plain bearing. Patent USA, no. 6.089.756, 2000

12. Germaneau A., Peyruseigt F., Mistou S., Doumalin P., Dupré J.-C. 3D mechanical analysis of aeronautical plain bearings: Validation of a finite element model from measurement of displacement fields by digital volume correlation and optical scanning tomography. Optics and Lasers in Engineering, 2010, vol. 48, no. 6, pp. 676-683.

13. Gao G., Yin Z., Jiang D., Zhan X. Numerical analysis of plain journal bearing under hydrodynamic lubrication by water, Tribology International, 2014, no. 75, pp. 31-38.

14. Ivanov V.A., Erkaev N.V. Analysis of elastic strain in a plain bearing. Fundamental Research, 2015, no. 6, pp. 241-245. In Rus.

15. Siluyanova M.V., Fertikov A.O. Calculation of the lubricant flow in the sliding bearing of an aircraft engine gearbox. Bulletin of Samara University. Aerospace engineering, technology and engineering, 2019, vol. 18, no. 2, pp. 75-88. In Rus.

16. Pugachev A.O., Ravikovich Yu.A., Ermilov Yu.I., Kholobtsev D.P., Matushkin A.A. Modeling the characteristics of oil and gas plain bearings using computational gas dynamics. Bulletin of the Samara State Aerospace University named after academician S.P. Korolev, 2013, no. 3 (41), pp. 211-221. In Rus. 
17. Hlaváč J., Čechura M. Direct drive of $25 \mathrm{MN}$ mechanical forging press. Procedia Engineering, 2015, no. 100, pp. 1608-1615.

18. Burdukovsky V.G., Inatovich Yu.V. Oborudovanie kuznechnoshtampovochnykh tsekhov. Krivoshipnye mashiny [Equipment forging and stamping shops. Crank Machines]. Yekaterinburg, Ural University Press, 2018. 168 p.

19. Garkunov D.N. Tribotekhnika [Tribotechnology]. Moscow, Mashinostroenie Publ., 1999, 336 p.

20. Zhivov L.I., Ovchinnikov A.G., Skladchikov E.N. Kuznechnoshtampovochnoe oborudovanie [Forging and stamping equipment]. Moscow, N.E. Bauman MSTU Publ. House, 2006. 560 p.

21. Chval Z., Cechura M. Optimization of power transmission on mechanical forging presses. Procedia Engineering, 2014, no. 69, pp. 890-896.

22. Bocharov Yu.A. Kuznechno-shtampovochnoe oborudovanie [Forging and stamping equipment]. Moscow, Academiya Publ. Center, 2008. 480 p

\section{Information about the authors}

Stanislav V. Pilipenko, Cand. Sc., associate professor, Polotsk State University.

Victor A. Frutski, Cand. Sc., associate professor, Polotsk State University.

Aleksandr V. Dudan, Cand. Sc., associate professor, Polotsk State University.
23. Frutsky V.A. Antifriktsionny material iz legirovannoy borom $i$ medyu chugunnoy struzhki dlya podshipnikov skolzheniya. Diss. Kand. nauk [Antifriction material from alloyed with boron and copper cast iron shavings for plain bearings. Cand. Diss.]. Novopolotsk, 2006. 135 p.

24. Shtempel O.P. Intensifikatsiya diffuzionnogo legirovaniya metallicheskikh poroshkov dlya zashchitnykh pokrytiy $v$ podvizhnykh poroshkovykh smesyakh. Avtoreferat Dis. Kand. nauk [Intensification of diffusion alloying of metal powders for protective coatings in movable powder mixtures. Cand. Diss. Abstract]. Novopolotsk, 2003. 23 p.

Received: 12 December 2020. 